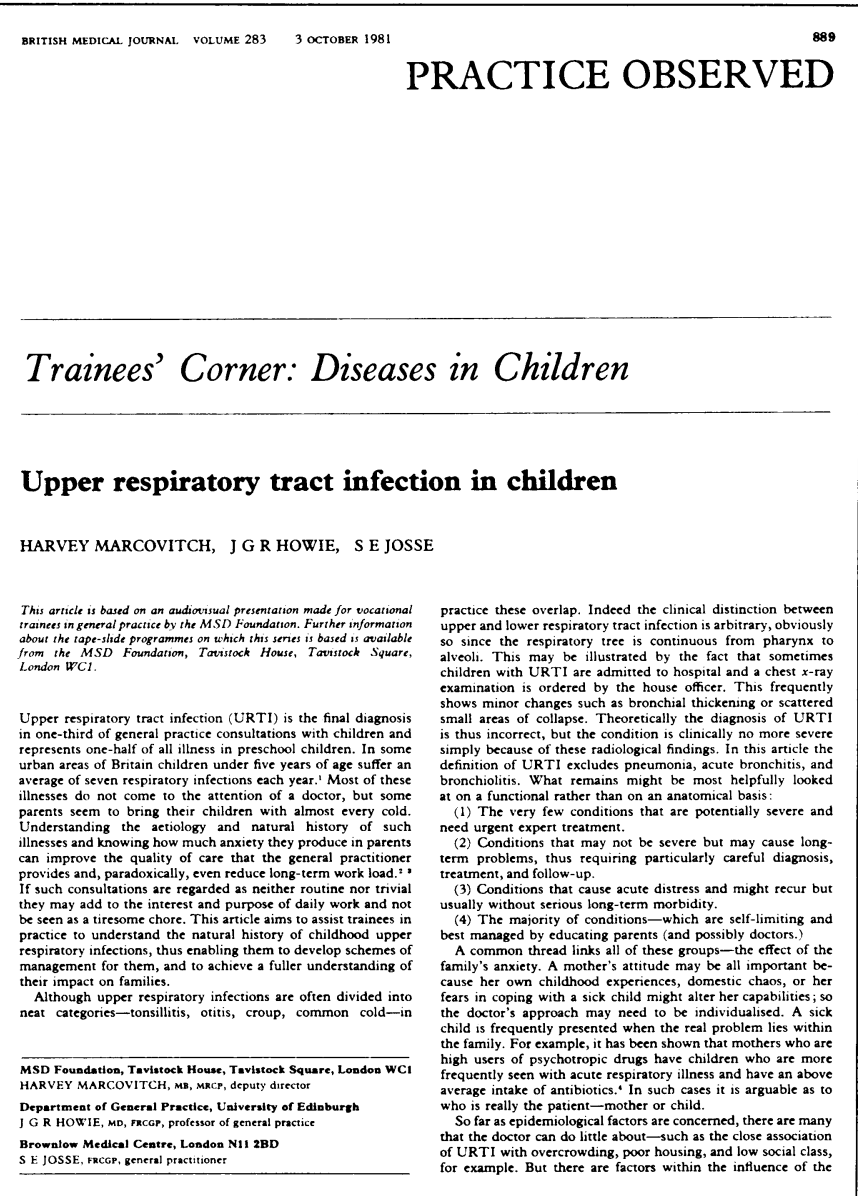

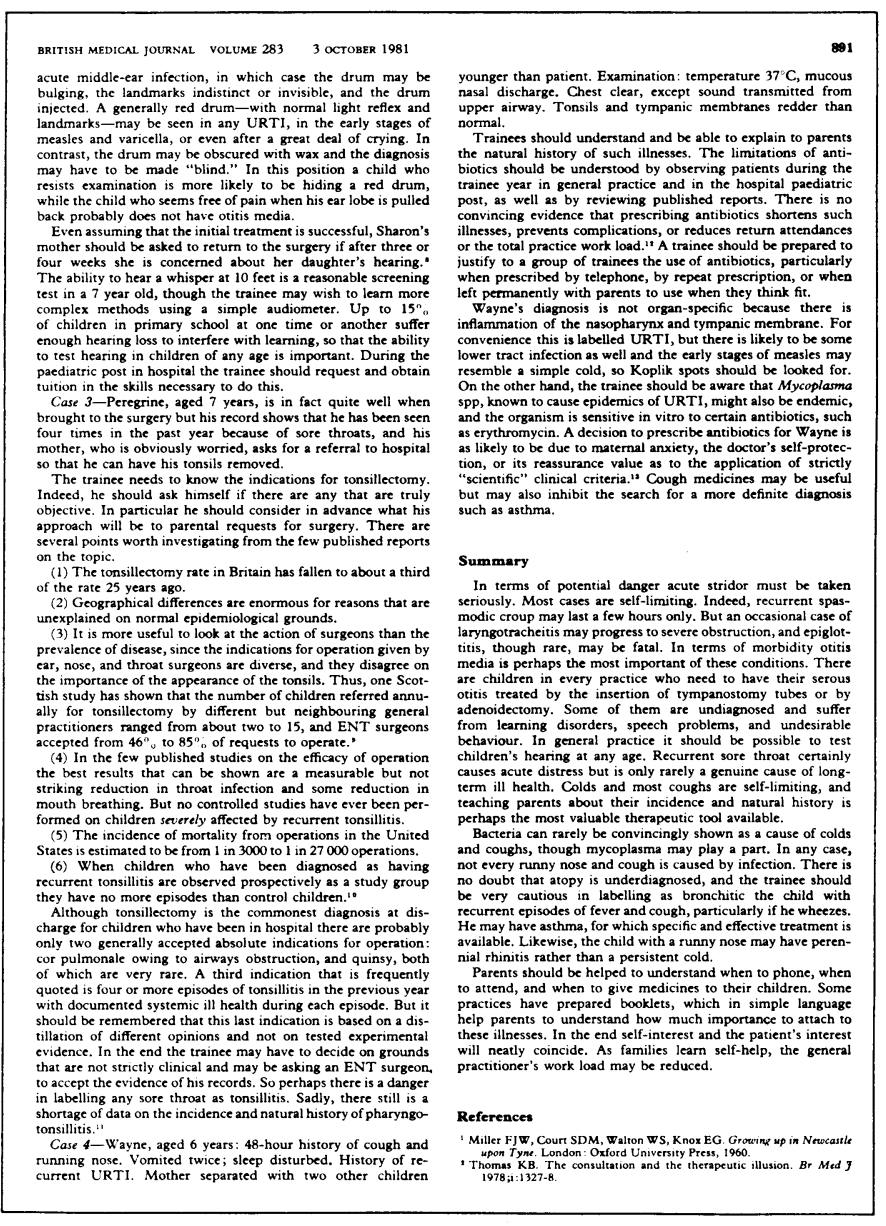

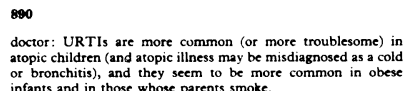

Four patients

Four patents are discussed in this article, each typifies a
common problem that che trainee should be able to deal with

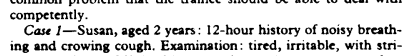

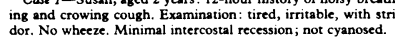

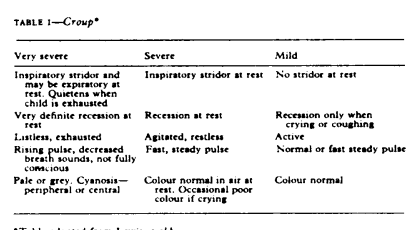

The major considerations before setring on a diagnosis of

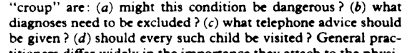

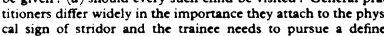

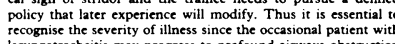

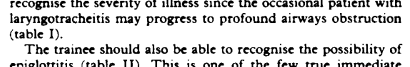

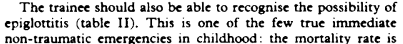

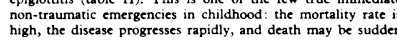

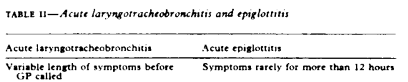

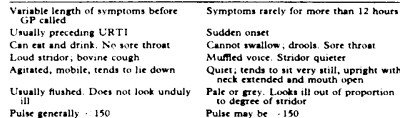

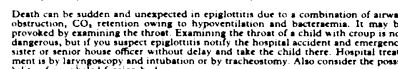

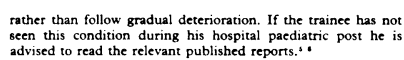

BRTIISH MEDICA JOURNAL VOLUME 283 3 OCTOBER 1981 Bearing in mind these two major complications of what is
eencerally a benign discase, trainers and course organisers need to

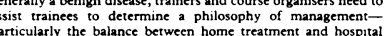

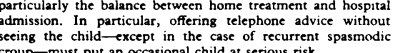

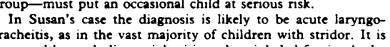

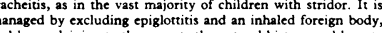
and by explaining to the parents the natural history and how to

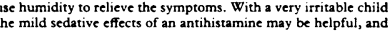

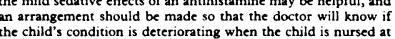

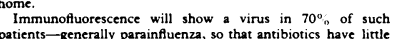

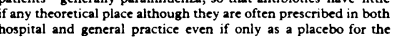
doctor or relatives.
Case 2 -Sharon, aged 7 years: late night telephone call to say

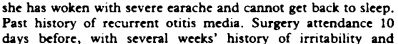
days before, with several wecks' history of irrtability and The questions that should arise in the traince's mind on

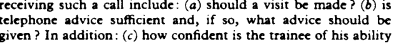
given? In addition: (c) how conident is the traince of his ability
to make an accurate diagnosis using an auriscope? (d) what ireatment and follow-up in is adequare?
The overriding need is to relieve pain and allow the child to decongestant may be helpfoul though the means by which it works is not clear. Pain relice is more important than the
nemediate use of an antibiotic, so a decision on the latter can wait until the child is seen, prefecrably at the next surgery iession (or the next morning, if a weckend). Certainly a child
with acurte suppurative otitis media should be treated with an

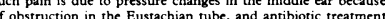
is unnececssary. If if an antibiotic is used it should be chosen by
ferring to table III.

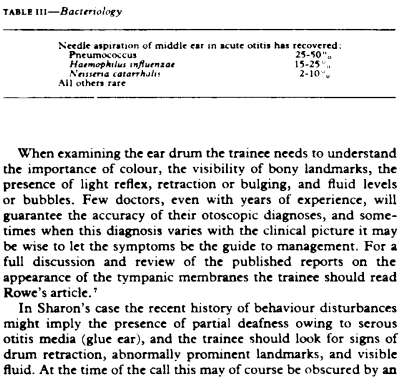

$\$ 2$

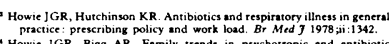

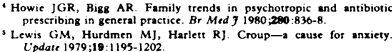

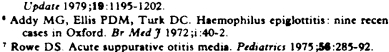

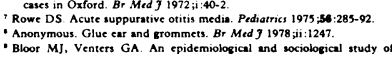

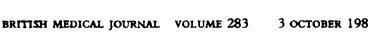

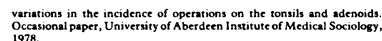

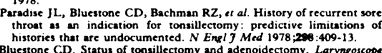

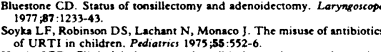

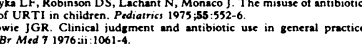

\section{New Idea}

\section{Simple SOAP system}

J S BHOPAL

I report on a new method of problem-orientated record keeping
based on the SOAP system- - subjective, objective, assessment plan. The SO SO S: Feels tired and feverish $\times 2 / 7$. Dry cough. Runny nose.
O: $P=96 /$ min. $T \sim 37 \cdot 3^{\circ} \mathrm{C}$ by mouth. Throat infected, en O: $\mathrm{P}-96 / \mathrm{min}$. T $~-37.3^{\circ} \mathrm{C}$ by mouth. Throat infected, ear
drums normal, chest clear. A: Viral upper respiratory infectio

P. Bed rest. Ample oral fluids. Aspirin every 6 hours as
required. Decongestant/2ncihistamine preparation. This way of recording medical information certainly leads to
an organised chart, compared to previous methods of recordkeeping. As the record envelope grows thicker with time,

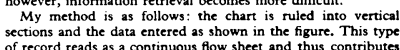
of record reads as a continuous flow sheet and thes contributea
to continuity of patient care. One has only to glannce down the assessment column and a summary of the patient's problems
is there. Reading the plan column gives a clear idea of the is there. Reading the plan column gives a clear idea of the
druss the patient has been prescribed
This system of record-keceping takes no more time than the conventional SOAP method. The results of $x$-rays and other
investigations are inserted in the asssessment column-in
differstions

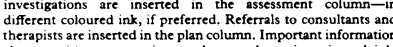
therapists are inserted in the plan column. Important informatio
about positive or negative results may be writen in red inl

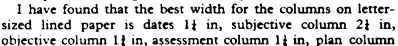

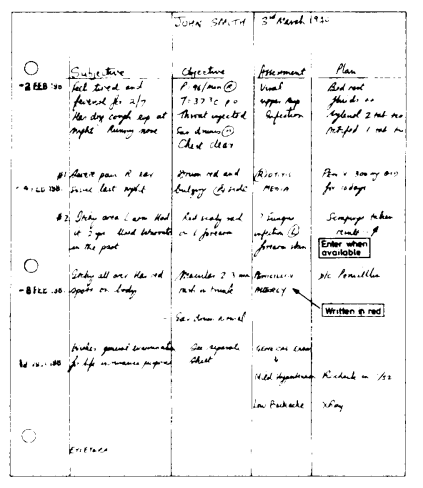

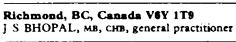

